\title{
LOS MUNDOS SEMÁNTICOS Y EL OBJETO ESTÉTICO. PROPUESTA DE LECTURA DEL ESPECTÁCULO TEATRAL
}

\author{
Luana Stoica
}

Teatro Judío Estatal

\begin{abstract}
Se dice que el arte es el ámbito de las apariencias, de las ilusiones, y lo que llamamos Bello igualmente puede ser considerado como aparente e ilusorio. [...] Por lo tanto, si el arte es una apariencia, tiene una apariencia que le es propia, no una apariencia pura y simplemente. [...] Sabemos que la verdadera realidad existe más allá de las sensaciones que percibimos directamente. Por lo tanto, el calificativo ilusorio se aplicaría más bien al mundo exterior que a la apariencia del arte.
\end{abstract}

Hegel, Estética I

El sentido de todo acontecimiento teatral se construye de manera dinámica, durante su recepción, mientras proyecta un mundo posible, imaginado y representado físicamente en escena, sobre las estructuras psíquicas del espectador. De esta manera estamos permanentemente ante dos «universos»: uno físico, resultado de la emergencia escénica del hecho teatral, y otro psíquico, resultado de la proyección psíquica de los datos perceptivos de acuerdo con las estructuras cognitivas del 
sujeto receptor. Entre estos dos «universos» hay una relación dinámica de conflicto e interacción continua, relación que se concreta en un proceso de semiosis.

La calidad de lectura de los signos escénicos depende de la competencia semiótica del individuo que, partiendo de la percepción del objeto tal y como se da a los sentidos, procede a una reorganización del material perceptivo según esquemas cognitivos específicos, muy potenciados afectivamente.

A continuación nos proponemos sugerir una lectura del espectáculo teatral en una clave cognitiva, semio-fenomenológica.

\section{NOCIONES PRELIMINARES}

Por su especificidad, el arte está permanentemente bajo la impronta de la dialéctica subjetividad/objetividad, y su aspecto inefable no hace más que potenciar esta dinámica. Vamos a empezar, por lo tanto, por esbozar el marco del paradigma semio-fenomenológico a partir del cual se va a abordar la recepción del objeto estético.

La fenomenología (en la línea de Husserl) se propone poner de manifiesto la experiencia humana como algo diferente del conocimiento del mundo real y se refiere a una «objetividad de la mente», situada más allá de la objetividad del mundo real. Se crea de esta manera la posibilidad de estudiar esta «objetividad de la mente» a través de un análisis introspectivo de las propiedades estructurales de la experiencia como tal. La objetividad fenomenológica tiene en cuenta las estructuras conceptuales-estructuras con significado, que difieren de la estructura de las entidades del mundo real y no dependen ontológicamente de las manifestaciones lingüísticas. Las estructuras conceptuales son, en general, pre-intencionales y existen en la conciencia interpretativa durante la descodificación de las expresiones intencionales transmitidas por el razonamiento inferencial, que persigue postular un mundo posible que convalide el hecho considerado.

Este cuadro fenomenológico se constituye en una metodología cuyo soporte ontológico lo da la semiótica, teniendo como objeto los pro- 
cesos que tienen lugar en la conciencia de un sujeto-intérprete cuando se da el encuentro del significado con el mundo de la experiencia, durante toda lectura de primer grado ${ }^{1}$.

Podemos considerar el sentido como una causa eficiente que se manifiesta a través de una significación expresiva (hacer externo algo interno, por medio de un signo), o de una significación de representación, impresiva (hacer interno algo exterior, por medio de un signo). El campo interno es de naturaleza psíquica (el espíritu, «la mente» del sujeto), mientras que el externo es de naturaleza física (el mundo).

\section{PERCEPCIÓN, COMUNICACIÓN, AFECTO}

La vida física, social y psíquica del hombre se desarrolla bajo el signo de una permanente relación con tres universos semánticos distintos, basados en condiciones ontológicas específicas de existencia. Esto caracteriza tres formas de ser: perceptiva, comunicacional e imaginativa, correspondientes a unas dimensiones esenciales de la existencia humana.

Partiendo del modelo elaborado por P. A. Brandt (1990a) para el estudio de la semántica de la metáfora, vamos a proceder a la adaptación de esos instrumentos de trabajo para abordar la experiencia estética.

Sean, por consiguiente, $M 1, M 2$ y $M 3$ los tres mundos semánticos correspondientes a las tres formas de ser, arriba mencionadas, donde:

$>M 1$ representa el mundo físico-semántico, basado en la percepción, limitado por la psicología del individuo y por su corporalidad fisiológica y cuyos elementos están centrados en las sensaciones. Es un mundo puramente físico y sus elementos son cuantificables.

${ }^{1}$ Cualquier mundo real admite una lectura de I grado (signo para el objeto O) y una de II grado (indicación de la naturaleza del interpretante). 
$>M 2$, representa el mundo socio-semántico, basado en la comunicación y no-limitado por la experiencia individual (las informaciones se combinan libremente en visiones y conceptos que pertenecen a unos niveles superiores de la existencia social-grupos, culturas). $M 2$ implica el cuerpo social y sus elementos se expresan en términos de acciones. Este mundo intercepta tanto la esfera física, en su realidad material, como la psíquica, por medio de la proyección (no-marcada afectivamente) en la conciencia de los actores sociales de las interacciones que tienen lugar ahí.

$>M 3$, representa el mundo psico-semántico, emocional, en cuya base está la imaginación. M3 implica el cuerpo emocional, imaginario, y sus elementos se encuentran bajo el imperio de las emociones. Se caracteriza por un alto grado de subjetividad.

Cada uno de estos tres marcos referenciales puede ser puesto en correspondencia con estructuras conceptuales «puras» que se estructuran en estados (intervienen en las representaciones descriptivas, por espacialidad icónica), en acontecimientos (constitutivos de las representaciones dinámicas, por temporalidad icónica) y campos (términos de contenido, de relación y condición, interviniendo mediante iconos espacio-temporales). Estas estructuras conceptuales intervienen, al nivel del interpretante, en el marco del proceso de «lectura» de un signo dado, cualquiera que fuera la naturaleza de éste. Lo mismo se puede decir de las proyecciones aferentes a ellas en los tres mundos semánticos:

\begin{tabular}{|c|c|c|c|c|c|}
\hline Notación & Características & base & manifestación & observaciones & proyecciones \\
\hline M1 & macro-física & percepción & sensorial & $\begin{array}{c}\text { limitada } \\
\text { fisiológicamente }\end{array}$ & $\begin{array}{l}\text { véase } \\
\text { fig. } 2\end{array}$ \\
\hline M2 & $\begin{array}{l}\text { inter-psíquica, } \\
\text { social }\end{array}$ & comunicación & $\begin{array}{l}\text { dinámica, } \\
\text { inter-activa }\end{array}$ & $\begin{array}{l}\text { no-limitada por } \\
\text { la experiencia } \\
\text { individual }\end{array}$ & “ \\
\hline M3 & $\begin{array}{l}\text { intra-psíquica, } \\
\text { emocional }\end{array}$ & imaginación & $\begin{array}{l}\text { emocional, } \\
\text { imaginativa }\end{array}$ & $\begin{array}{c}\text { el cuerpo } \\
\text { imaginario }\end{array}$ & “ \\
\hline
\end{tabular}

Figura 1: Los mundos semánticos 


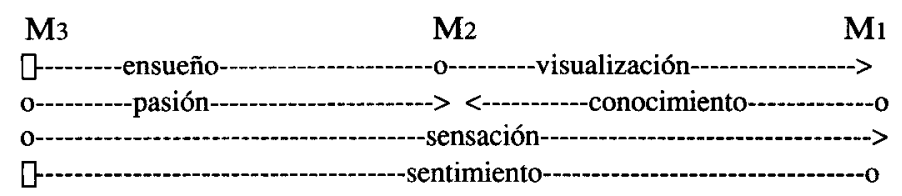

Figura 2: Las proyecciones aferentes a los mundos semánticos.

Aunque la percepción, la comunicación y lo imaginario funcionan independientemente, el elemento cultural deja su huella en ellos, generando conexiones específicas, que se manifiestan por medio de proyecciones semánticas de un elemento x de $M j$ (donde $\mathbf{j}, \mathbf{k} \in\{1,2,3\}$, $\mathrm{j}$ \# k) y por proyecciones de las estructuras conceptuales en estos tres campos de experiencia. En el momento en el que estamos ante proyecciones fundamentales de las estructuras conceptuales, reforzadas por la existencia social, éstas van a ser confirmadas por la presencia de unas representaciones icónicas cristalizadas en expresiones lingüísticas.

Tomar contacto con el objeto que se ofrece para «lectura» al sujeto no es más que la etapa preliminar al conocimiento. El dato perceptivo, «las acciones-marco» de la percepción, las emociones y las imágenes, nacidas durante o después de la interacción sujeto/objeto, necesitan ser trabajados e integrados en una construcción, cuyo resultado es el conocimiento.

Nos encontramos ante un dispositivo abierto de conocimiento, cuyo objetivo no es el de integrar la individualidad manifiesta, que se le presenta al receptor, en un sistema que le otorgue un «valor» de tipo diferencial, sino el de descomponer esta individualidad, identificando los caracteres que la definen como figura, e integrándola luego en una red compleja de tramas que dirigen, de una manera más o menos flexible, el flujo del conocimiento.

Precisamos que la figura es una «unidad de recorte», dentro de la cual están retenidas las características que dan cuenta del contenido individual del objeto o del hecho considerado.

Llamamos trama a un principio normalizador de naturaleza inferencial que tiene como objetivo encuadrar en una configuración una individualidad, que se escapa de las normas anteriormente aceptadas.

Este tipo de actuación nos sitúa en el marco de una semiótica cognitiva, que privilegia la actividad inferencial en el detrimento de la de 
descodificación. El tipo de inferencia más adecuado a tal operación - y sobre todo al estudio del objeto estético- es lo que Peirce llama abducción.

En el marco del razonamiento de tipo abductivo, la imaginación juega un papel primordial. La espera semiótica responde a la noción lógica de costumbre, que hay en la base de cualquier idea de significación: «lo que una cosa significa es pura y simplemente la costumbre que comporta» (Peirce 5.400, 1990: 141). La convicción es el resultado de la abducción primaria, que opera en virtud de una afinidad entre conocimiento y verdad. «Es imposible tener en mente una idea que tenga alguna relación con otra cosa más que con los efectos sensibles imaginados de las cosas. La idea que tenemos de algo es la idea que tenemos de sus efectos sensibles.» (Peirce 5.401, 1990: 143).

Se puede hablar de conocimiento en los términos de un conjunto dotado con diferentes tipos de memoria y con un dispositivo de inferencia. «La operación pertinente dejará de ser «la descodificación» y será «la inferencia», un tipo de razonamiento que restituye una organización plausible, que podría saturar todas las exigencias de la figura» (Almeida, 1988: 29). Dicho de otra manera, se busca un principio unificador de los detalles memorizados, y la significación, a la que se llega a través de la abducción, va a implicar un mundo posible postulado para hacer plausible la figura encontrada.

\section{LA ESPECIFICIDAD DEL OBJETO ESTÉTICO}

Cada objeto estético se caracteriza por una fuerte carga afectiva, por su unicidad y singularidad, por su identidad (el título que lleva, la firma del autor, etc.) y por una semiosis ilimitada. Por medio de la sustitución, parcial o total, de la función y del significado funcional del objeto estético, el afecto mediatiza la percepción del receptor implicado en la contemplación de la obra de arte. Esta preponderancia del afecto hace que la recepción lleve la marca de lo imaginario y que sea mediada por las estructuras características del mundo emocional.

Las obras de arte son «leídas» como propuestas referenciales e invitan a una lectura ontológica. Este hecho encuentra su justificación 
en la característica de las obras de arte de tener un flujo de propiedades formales que se imponen a los sentidos de sus receptores respectivos. Se trata de un flujo de predicados (y no solamente de objetos en sí) que determina un archi-referente: el Mundo como tal. No se trata tanto de un mundo referencial posible (que designa una multitud limitada de estados interdependientes), como del mundo como realidad, que nos incluye en su materialidad al igual que nos rodea la inmanencia de una obra de arte. El significado no se puede mirar desde el exterior, ya que el Mundo es nuestro mundo, al que pertenecemos y del que no nos podemos separar más que por abstracción. Podríamos afirmar, por lo tanto, que el significado de la obra de arte tiene un aspecto atemporal al igual que el Mundo, en la acepción arriba mencionada, es atemporal.

La contemplación estética opera una trascendencia de la condición histórica del receptor, sacándolo de su tiempo histórico y transportándolo en un espacio emocional subjetivo, en el que el tiempo se somete a otras leyes. Esta «temporalidad» estética va a influir tanto en las proyecciones de las estructuras conceptuales en los tres mundos $M i$, donde i $\varepsilon\{1,2,3\}$, como en las proyecciones de $M 1$ y $M 2$ en $M 3$.

Los objetos estéticos tienen, por lo tanto, una aspectualidad afectiva y, por medio de una transformación fenomenológica, son extraídos de la organización social y singularizados. De este modo tiene lugar su transformación en un signo especial, «type»y «token» al mismo tiempo, que significan el conjunto de los efectos de un signo identificado como fuente de signos.

Este tipo de signos constituye el objeto del arte, del amor y del conocimiento. De éstos, el arte se individualiza por su capacidad de ser no sólo aisthesis, sino también amor y conocimiento al mismo tiempo.

$\mathrm{El}$ arte es una experiencia emocional intensa, un impacto subjetivo, siendo difícil de derivar de la estructura fenomenológica del aspecto objetivo de la contemplación de la obra de arte. La experiencia estética se caracteriza por una única emoción fundamental, cuya característica es la intensidad. La podemos llamar Emoción, subrayando que no se identifica con la alegría o con la tristeza; y la más cercana a su naturaleza es la categoría estética de lo Sublime. La subjetividad pura de la Emoción está relacionada con el objeto de la experiencia, el archi-referente Mundo, e implica un sentimiento intenso de la Presencia por medio de la identificación del receptor con el objeto de la contemplación estética: 
Convenciones

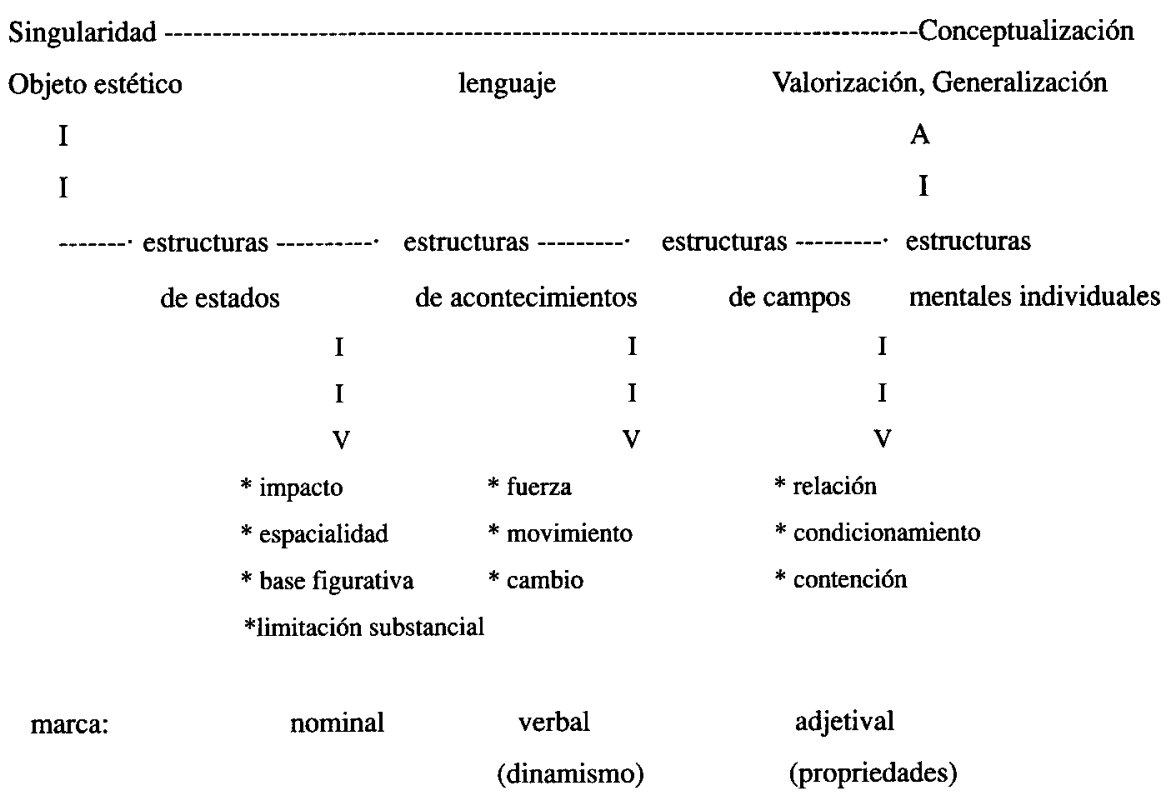

Figura 3: Lectura del objeto estético.

El objeto estético se construye o se evoca con la ayuda de los procedimientos artísticos o, dicho de otra manera, es un «universo de conocimiento inédito, irrepetible, denso (por «denso» entendemos que no se puede articular en elementos diferenciados-no hay alfabeto) y sin detalles ajenos a su simbolización» (Almeida, 1988: 399). Es lo que hemos llamado antes «configuración». La obra de arte no tiene rasgos pertinentes (que mantengan su claridad y el aspecto pertinente cuando se les saca del contexto de la obra), no puede ser reducida a un sistema, no posee una clave universal de descodificación. La operación de lectura de una obra de arte supone sumar todos los detalles a una hipótesis de organización individual. A veces, puede ser que los detalles retenidos no puedan asimilarse a unas estructuras conceptuales fundamentales, lo que afecta negativamente su transposición lingüística y el grado de puridad de la descripción de la experiencia estética. En cuanto a la pertinencia epistemológica de la estética, G. G. Granger (1968: 8) afirma que «vista como actividad, la creación estética es una de las tentativas humanas de sobrepasar la imposibilidad de sorprender teóricamente lo individual». 


\section{EL OBJETO ESTÉTICO TEATRAL}

La obra teatral ocupa un lugar aparte entre los objetos estéticos, debido tanto a la especificidad del lenguaje escénico, como a las particularidades de recepción de la representación teatral.

El arte del espectáculo se caracteriza por la voluntad de «mostrar». Aunque se realiza por medio de varios canales sensoriales, la recepción del acontecimiento teatral es predominantemente visual, el elemento verbal se percibe en un contexto de imágenes dado. El carácter polisémico de la imagen es mucho más fuerte que el de la palabra. De ahí, la dificultad de entrar en el mecanismo que gobierna el espectáculo en su acepción tripartita:

texto-representación-público.

Si el nivel del texto dramático entra en el juego de la adaptación de una metodología ya existente en la semiótica linguíística, el binomio representación/público plantea problemas especiales (sobre todo cuando los dos términos se miran bajo el aspecto de la dinámica que les une a lo largo del ritual espectacular).

Dado su carácter histriónico declarado, la comunicación primaria entre escena y sala tiene lugar al nivel del afecto, porque, conscientemente o no, el espectador está buscando la catharsis liberadora. A su vez, la sala potencia afectivamente la escena con sus reacciones, que tienen una función de feed-back para los intérpretes. Gracias a ello, la barrera linguística se ha demostrado superable a la hora de establecer la comunicación con el público, lo que demuestra una vez más que, de hecho, la comunicación con los espectadores es plural, teniendo raíces en las estructuras conceptuales profundas (el hecho es aún más evidente cuando la calidad del acontecimiento teatral es buena).

El acontecimiento teatral tiene como base un campo central predominantemente emocional (de tipo $M 3$ ), asegurado por el espacio escénico, en su calidad de circunstancia extra-lingüística esencial. Aunque el fenómeno teatral tiene lugar en $M 2$ (el mensaje se construye y comunica conforme a las convenciones, a los códigos y al lenguaje, operacionales en este nivel), la clave de su lectura se sitúa 
en el plano $M 3$. La realidad física de la escena, mundo de tipo $M 2$, soporta una proyección total en el mundo imaginario $M 3$-mundo de la finalidad como representación emocional-, en el que se inscribe la ficción espectacular. Estamos ante un dato perceptivo proyectado simultáneamente en $M 2$ y $M 3$. En realidad se percibe una realidad de tipo $M 2$ (los actores, el espacio de la escena, las interacciones físicas y verbales, etc.) que se proyecta en $M 3$ para ser «leída» (en términos de personajes, mundo representado, vivencia, etc.). La existencia de la convención teatral declarada, aceptada por el público, hace posible esta proyección total.

Estamos ante la dominación del mundo semántico intra-físico $M 3$, manifestada al nivel del afecto y de la imaginación, los otros dos mundos semánticos interviniendo por proyecciones en $M 3$ de las acciones y las descripciones correspondientes. La sintaxis escénica, vista como un conjunto, puede ser asimilada a una fenomenología emocional.

El mundo $M 3$ interviene tanto en el espacio escénico, poblado por personajes dramáticos, como en el proceso de «lectura» del espectador. La representación escénica recibe a su dramatis personae por medio de una proyección de unos acontecimientos de tipo $M 2$, dentro del cuadro escénico creado. La enunciación tiene lugar por medio de actos verbales o gestos corporales, efectuados por cuerpos imaginarios - apariciones mentales fantásticas de $M 3$, los personajes dramáticos-, interpretados por los actores que existen, actúan y sienten en un universo comunicacional real de tipo $M 2$-el mundo compartido-:

Escena

Público

M3: Universo ficticio

Personajes dramáticos

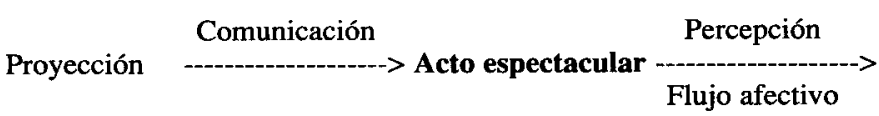

M2: Espacio de juego, decorado

Actores

$\begin{array}{lll}M 3 & M 1 & M 2\end{array}$

A

I

-feed back emocional-

Figura 4: Proyecciones semánticas en el «circuito teatral». 
Hay que mencionar el hecho de que la escena potencia una transferencia permanente de información desde $M 2$ hacia $M 3$. Se puede dar el caso en el que acontecimientos improvistos, surgidos en el marco del espacio de juego o que, por su efecto, generan reacciones por parte de los actores en su calidad de personas físicas, sean transferidos por el receptor al universo ficticio y leídos conforme a las claves de $M 3$. A veces, semejantes deslices semánticos (proyecciones de $M 2$ en $M 3$ ) pueden intervenir también en las relaciones entre actores.

\section{CONCLUSIONES}

Esta forma de abordar el arte del espectáculo tampoco logra, sin embargo, dar cuenta de la complejidad de ése. No obstante, el intento de aplicarla al análisis específico del proceso de la creación escénica, tanto a nivel teórico como a través del estudio de las puestas teatrales en escena concretas, puede ofrecer no solamente una mejor comprensión del fenómeno espectacular, sino también nuevas soluciones de explotación de su inmenso potencial.

Al mismo tiempo, abordar teóricamente el fenómeno teatral puede aportar su contribución a la extensión del conocimiento del mecanismo semántico que gobierna el proceso de significación, bajo cuyo signo se desarrolla toda la existencia humana.

La magia del teatro viene a subrayar el hecho de que las estructuras conceptuales superan la esfera del simple contenido cultural. La escena demuestra no solamente que existe significación fuera del lenguaje, sino también el hecho de que las significaciones expresadas pueden hacer referencia a algo más de lo que denotan.

El objeto estético, en su complejidad, dispone de múltiples valencias cognitivas que superan el simple contacto de un sujeto conocedor con un mundo posible propuesto para la recepción. La percepción del mensaje estético se relaciona con la dialéctica entre la fidelidad y la libertad de interpretación - al nivel del destinatario - y con la de entre forma y apertura - al nivel del mensaje-. Los efectos de la experiencia estética son mucho más profundos de lo que se podría creer a primera vista, pudiendo generar re-evaluaciones de los esquemas cognitivos de lectura del mundo que rodea, re-orientaciones de las estructuras conceptuales o incluso modificaciones del sistema de valores del receptor. 


\section{Referencias bibliográficas}

AlmeIda, I. (1988). Sémiotique abductive. Poetica et Analytica 5. Aarhus: Aarhus Universitet.

BRANDT, P. A. (1990a). «Cognition and the Semantics of Metaphor». Conference. Urbino: Centro Internazionale de Semiotica e Linguistica (manuscrito).

- (1990b). Dynamiques du sens. Poetica et Analitica 10. Aarhus: Aarhus Universitet.

Granger, G. G. (1968). Essai d'une philosophie du style. Paris: Colin.

PEIRCE, Ch. S. (1990). Semnificatie si actiune. Bucuresti: Humanitas.

THOM, R. (1972). Stabilité structurelle et morphogénèsé. Reading: W.A. Benjamin. 